\title{
"O escuro das cores, na pele afrodescendente, herdeira das dores"*: dimensóes do racismo no contexto de assistência ao parto
}

\section{| ${ }^{1}$ Kelly Diogo de Lima, ${ }^{2}$ Liana Lewis, ${ }^{3}$ Tereza Maciel Lyra |}

Resumo: Partindo de uma pesquisa mais ampla sobre as vivências de mulheres negras na assistência ao período gestacional e parto, este artigo aborda alguns aspectos do racismo na rotina de atenção à mulher negra durante este ciclo. Trata-se de uma pesquisa empírica de abordagem qualitativa com mulheres e mães que se autodeclaram negras e antirracistas. Nas narrativas, os pontos apresentados envolviam, na sua maioria, estereótipos associados ao corpo negro construídos sob um imaginário social racista. Nas relaçóes interpessoais, discursos permeados por estereótipos racistas desumanizam a mulher negra, gerando barreiras na sua saúde reprodutiva.

> Palavras-chave: mulheres negras; racismo; discriminação racial na saúde; assistência ao parto; direitos reprodutivos.

\author{
${ }^{1}$ Instituto de Medicina Social, \\ Universidade do Estado do Rio de \\ Janeiro. Rio de Janeiro-RJ, Brasil \\ (k.diogolima@gmail.com). \\ ORCID: 0000-0002-4338-9410 \\ ${ }^{2}$ Centro de Filosofia e Ciências \\ Humanas, Universidade Federal \\ de Pernambuco. Recife-PE, Brasil \\ (lianalew@hotmail.com). \\ ORCID: 0000-0001-5876-7579 \\ ${ }^{3}$ Instituto Aggeu Magalhães, \\ Fundação Oswaldo Cruz. Recife- \\ PE, Brasil (terezalyra@cpqam. \\ fiocruz.br). \\ ORCID: 0000-0002-3600-7250
}

Recebido em: 17/12/2019 Aprovado em: 13/03/2020 Revisado em: 24/03/2021

\footnotetext{
* Trecho da música Tambor, do artista Kamau feat. Rincon Sapiência e Thalma de Freitas (2008).
} 


\section{Introdução}

O presente artigo é parte da reflexão da dissertação de mestrado intitulada Vivências de Mulheres Negras na Assistência ao Parto: Vulnerabilidades e Cuidados. Além de identificar as práticas de cuidado e a assistência profissional na gestação, parto e nascimento, ouvimos as mulheres para identificar em que medida sofreram ou percebem a discriminação racial nos serviços de saúde. Para este artigo, trataremos com mais ênfase do último tema, analisando como persistem certas construçóes históricas baseadas na ideia de raça.

Fazendo uma breve análise da nossa história racial, e do racismo no contexto brasileiro, prevalece a crença de vivermos em uma ampla harmonia de cores e etnias. Crescemos cegos diante da realidade da raça em nosso país. No entanto, um olhar mais atento constata que, ao mesmo tempo em que afirmamos não haver distinçóes com base na raça, ou cor da pele, vivemos em uma sociedade estruturada pelas relaçóes e conflitos raciais que sentenciam o acesso ao poder, à justiça, à terra, à moradia, à saúde, entre outros.

O escritor camaronês Achille Mbembe (2014) elucida que é durante o período das grandes navegaçóes pelo atlântico, do colonialismo europeu, que o negro passa a ser sujeito de raça, sendo expelido da ideia de humano. O pensamento colonial destituiu o negro da sua humanidade, atribuindo-lhe pulsóes irracionais e uma sexualidade primitiva. Faltava algo ao negro africano, assim como um buraco, precisava ser preenchido. Seu corpo foi tomado como força de trabalho escravo, o que metaforicamente, segundo o escritor, se assemelha a um mineral extraído da terra e convertido em riqueza na Europa. A raça é criada como um "princípio de segregação, ou de purificação da sociedade" (MBEMBE, 2014, p. 101), é um marcador social da diferença, antes de um conceito biológico, trata-se de uma construção histórica e social. O racismo não pode ser explicado em termos biológicos, “[...] o racismo não é biológico, mas discursivo. Ele funciona através de um regime discursivo, uma cadeia de palavras e imagens que por associação se tornam equivalentes: africano- África selva - selvagem - primitivo - inferior - animal - macaco." (KILOMBA, 2019, p. 130).

Tal pensamento, quando aplicado no cenário brasileiro, adquire contornos bastante específicos que resultam nos efeitos da normalização, e institucionalização do que se denomina "racismo à brasileira". Esse racismo se utiliza de etiquetas e discursos que velam sua existência. Eufemismos, chistes, deslocamentos semânticos 
garantem que a violência racial se efetive sem ser muitas vezes reconhecida, discutida ou denunciada. A história do Brasil é marcada por um aparato estatal racista cujos contornos se desenvolveram desde os tempos coloniais. Atos como a criminalização de festas organizadas por negros, a prática da capoeira e a proibição de frequentarem a escola, foram instituídos na época (SILVA JR., 2008). Na República, cria-se mecanismos para a proibição de práticas religiosas afro-indígenas, como a prescrição, para fins terapêuticos, de plantas e ervas. Em conjunto, sacerdotes e sacerdotisas necessitavam de um alvará e licença para abrir terreiros, casas de $\grave{A} s$, obrigatoriedade que foi revogada apenas na Constituição Federal de 1988 (FERNANDES, 2017).

Mas é no Estado Novo que a supressão da pluralidade racial da sociedade brasileira se efetiva como projeto oficial. As análises acadêmicas sobre as relaçóes raciais no país foram inicialmente formuladas a partir de uma perspectiva freyriana. Na obra Casa-Grande e Senzala, do autor Gilberto Freyre, em 1933, os papéis do senhor branco severo e ao mesmo tempo paterno e do negro gentilmente servil e fiel, enaltecem uma suposta harmonização dos conflitos entre escravizados e brancos da elite portuguesa, impunha-se a época uma fictícia ideia de "boa-escravidão" (SCHWARCZ, 2012, p. 51).

A essa tentativa de alicerçar uma harmonia racial no país foi denominada pelo sociólogo Florestan Fernandes (2008) de mito da democracia racial. Para o sociólogo, o mito finda por elidir a violência racial que estrutura nossa sociedade, ao mesmo tempo em que culpabiliza os negros por sua situação de subalternização. Se estes ocupam os estratos mais baixos do tecido social, são naturalmente responsabilizados por seu fracasso em ascender socialmente. O sucesso, ou seu infortúnio, é reflexo unicamente dos seus esforços e de seu caráter.

O racismo atravessa diversos eixos e foi construído e aprimorado durante a história. Dentre as dimensóes do racismo destacamos o interpessoal, que se expressa em condutas discriminatórios e preconceituosas, intencionais ou não, alimentando visões estereotipadas contra o negro, e o institucional, que parte da dimensão individual para a estrutural, é possivelmente a dimensão mais negligenciada de racismo. Este último, as normas e condutas institucionais produzem a exclusão de grupos e pessoas relativa à sua cor ou origem étnica (WERNECK, 2016). Como nos alerta Frantz Fanon (2008), as instituiçóes parecem ser à mulher e ao homem negro o seu pior inimigo.

Com o intuito de discutir a questão racial e suas dimensôes, expressôes, no contexto de assistência ao parto, buscaremos responder, nas partes que se seguem, as 
seguintes perguntas: como o racismo pode intervir na qualidade da atenção ao parto de mulheres negras? Quais suas percepções, medo e quais são suas vivências diante das rotinas obstétricas e institucionais no ambiente hospitalar?

\section{Percurso metodológico}

Foi realizada pesquisa empírica de abordagem qualitativa, cujo universo dos sujeitos são mulheres que se autodeclaram negras (pretas e pardas), maiores de 18 anos, com filhos/as menores de dois anos e que em algum momento da gestação ou parto recorreram aos serviços do Sistema Único de Saúde (SUS). Outro importante critério para a escolha das participantes, se refere ao fato de haver nelas um reconhecimento e construção de uma identidade negra positiva e de atuação na luta antirracista.

Para o encontro com essas mulheres, resolvemos eleger como território inicial um terreiro de matriz africana localizado no município de Olinda, estado de Pernambuco. As primeiras entrevistadas foram indicadas por lideranças locais, as primeiras indicavam outras mulheres da sua rede de contatos ao final de cada entrevista. Respeitando os critérios de inclusão, a pesquisa entrevistou mulheres de outras cidades, uma participante do Rio de Janeiro e outra de nacionalidade angolana, morando no Brasil há quatro anos. O período de campo foi de dois meses, transcorridos entre outubro e novembro de 2017.

Foram feitas entrevistas semiestruturadas que abordaram questóes sobre as vivências das mulheres no período gestacional, à assistência no pré-natal e ao parto, bem como sobre a experiência do racismo nos serviços de saúde. Depois de transcritas na íntegra, todas as falas foram analisadas a partir da técnica de Análise de Conteúdo de Laurence Bardin (2011). A partir das entrevistas transcritas, realizamos um estudo aprofundado do material empírico definindo este em categorias com base nos objetivos do estudo e hipóteses levantadas, destacando as informaçóes para efetivar uma análise reflexiva e crítica.

A pesquisa obedeceu aos critérios éticos e foi aprovada pelo Comitê de Ética e Pesquisa do Instituto Aggeu Magalhães (IAM/Fiocruz), sob o CAAE: 72762817.5.0000.5190. Com o objetivo de respeitar o anonimato foi sugerido às entrevistadas a escolha de seus nomes fictícios. Outros nomes citados pelas participantes, como familiares, foram substituídos pela autora da pesquisa. 


\section{Resultados e discussão}

$\mathrm{Na}$ pesquisa, foram ouvidas nove mulheres, deste total escolhemos analisar as narrativas de quatro delas por oferecerem falas variadas acerca das suas percepçóes e experiências de racismo na atençáo ao parto. Loní, 22 anos, cursou até o ensino médio, tem dois filhos e é candomblecista; Raquel, 25 anos, cursava uma pósgraduação, tem um filho e afirmou não ter religião; Magnólia, 32 anos, tem ensino superior, uma filha e também é candomblecista, é do Rio de Janeiro, e Zizi, 26 anos, ensino superior, tem um filho e afirmou ser católica, de Angola, país africano. Todas afirmaram serem heterossexuais e estavam em união estável. Em relação à renda da casa, a menor renda mensal relatada foi de 937,00 reais e a maior de 3,700 reais. Magnólia era a única que possuía plano privado de saúde, mas realizou a maioria das consultas de pré-natal e o parto no serviço público. As outras participantes tiveram assistência durante toda a gestação, parto e puerpério na rede pública.

Os relatos foram organizados em torno de três temas: i) Discriminação contra a estética negra; ii) $\mathrm{O}$ mito da incomum capacidade para resistir a dor e iii) A rotina hospitalar e o racismo religioso.

\section{Discriminação contra a estética negra}

Uma das marcas no racismo é sua aversão a uma "estética negra", cor da pele e tipo de cabelo ocupam papéis importantes na identidade negra e na maneira como o/a negro/a é visto na sociedade. O cabelo é uma forte marca identitária, cabelo e corpo são pensados a partir de padróes sociais, neste aspecto ambos são expressóes simbólicas da identidade racial brasileira. Para as mulheres negras, raça e gênero se intercruzam nas formas como pensam sobre cultura, beleza e estética negra (GOMES, 2006).

A seguir, as narrativas mostram comentários preconceituosos por parte dos profissionais de saúde diante dos cabelos.

Ela disse: "a senhora vai ter que tirar seu cabelo!" Perguntei por que eu tenho que tirar meu cabelo e ela disse que é porque "isso" faz mal pra criança. Mas como eu ia tirar meu cabelo? Ela insistiu: "não porque, veja só, as mães que 'tão' internadas a maioria não tem um cabelo assim, e outra, faz mal para as crianças e as mães” (Loní).

Tinha muita pergunta em torno do meu cabelo, do tipo "por que eu fiz isso, como é que fazia isso, se isso lavava?” A enfermeira, que também era negra, me perguntava se eu lavava meu cabelo (Raquel). 
$\mathrm{Na}$ primeira fala, Loní descreve ter sofrido preconceito por usar, na ocasião, "tranças afro", box braids, associadas a algo sujo e que não condizia com o ambiente da maternidade. Tais questôes sobre a aparência e higiene dos fios também é observado na fala da enfermeira da unidade de saúde da família, que realizou as consultas prénatais de Raquel. Aos nove meses de gestação, a entrevistada relatou que teve uma conversa com seu companheiro sobre a possibilidade de cortar seu dreadlock.

"Se a enfermeira chegar lá e vê um negócio desse ela vai me deixar no canto [...] tu sabe
como é, e como é com a gente?!” Ele também é negro e por isso corria o risco deles não
deixarem meu companheiro entrar e, lá dentro, fazerem o que quiserem comigo. Mas
acabamos conversando e eu decidi por não cortar. Mas eu tinha muito medo por causa
disso (Raquel).

Havia ainda a preocupação de náo permitirem que seu companheiro entrasse na sala de parto com ela por também ser negro e, estando lá dentro, ser "esquecida” ou sofrer algum outro tipo de violência. Nota-se que há um medo em ser discriminada por algo que referencia ainda mais sua negritude. O cabelo negro, apontado como sujo, parecia não condizer com o ambiente hospitalar. Para Nilma Gomes (2006), o cabelo da mulher negra, naturalmente crespo, opera como signo da identidade racial e de resistência por ser uma parte do seu corpo constantemente negado e confrontado pelo racismo.

A construção histórica do racismo impóe, além de uma dominação econômica e cultural ocidental, uma estética branca. Para as mulheres negras o cabelo afro pode ser tanto um estilo ou posição política. Exibir um cabelo natural, com suas variaçôes e texturas, é uma forma de confrontar esse modelo imposto e provocar conflitos que muitas vezes repercute em atos de discriminação racial. O cabelo negro visto como "ruim" e "sujo" é uma expressão do racismo. O cabelo é uma marca de procedência, um traço de identificação, juntamente com a cor da pele marca quem é negro em nossa sociedade (GOMES, 2006). A escritora Grada Kilomba (2019) enfatiza como o cabelo natural pode significar um instrumento de consciência política. Os negros da diáspora estão marcando sua posição de negação às opressões raciais. Tornar-se "muito negra" é mostrar muitos sinais de negritude, que pode significar também "sinais de independência e descolonização em relação às normas brancas.” (KILOMBA, 2019, p. 127).

Conotações negativas sobre os elementos do corpo negro é o lócus de afirmação da branquitude. A necessidade de embranquecer-se foi gravada na consciência 
do negro como forma de alcançar a beleza, a moral e a pureza (SOUZA, 1983). Dispositivos nutrem e disseminam a crença de que tudo no branco é desejável e dispóe de privilégio, seu corpo, sua linguagem e a sua riqueza. E sendo um sujeito estranho a si mesmo, o negro vai desejar torna-se o outro (MBEMBE, 2014). No imaginário branco a negritude é repugnante. Cria-se uma fantasia sobre o sujeito negro e ela geralmente é suja e selvagem (KILOMBA, 2019).

Sobre o negro, "sua constituição passa pela negação do corpo, ou de parte dele, pelo branqueamento". Assim, negar esse corpo estigmatizado, ou elementos dele, é negar uma construção do "eu”, e assim o ideal do "eu" é construído em torno do "outro". O branqueamento, ideologia que se consolida enquanto projeto de naçáo brasileira, depositava no cruzamento racial de imigrantes europeus a possibilidade de construçáo de uma nova identidade. $\mathrm{O}$ mulato, sendo deslocado de qualquer origem, se tornou a primeira escala para elidir a raça negra no Brasil (SALES JR., 2006, p. 234).

As políticas de branqueamento demonstram uma clara tentativa de genocídio da raça negra e indígena no Brasil. O cruzamento racial proposto não contemplaria todas as raças, a incorporação de imigrantes europeus, não sendo qualquer europeu, e exclusão de africanos e asiáticos no território nacional, nasceu como uma estratégia de clarear os corpos. Afrânio Peixoto, médico eugenista e representante da intelectualidade brasileira do século XX, previa um "melhoramento" da "raça brasileira" por meio da miscigenaçâo: "Trezentos anos talvez, levaremos para mudar de alma e alvejar a pele, e se não brancos, ao menos disfarçados, perderemos o caráter mestiço" (NASCIMENTO, 2016a, p. 88). É preciso revisitar a história para compreender a verdadeira origem dos conflitos. Ao fazermos, percebemos o quanto estamos marcados por estigmas violentos de raça.

Retomando as falas dos profissionais, se assentimos que "a linguagem não expressa apenas ideias e conceitos, mas tudo que se pensa” (THEODORO, 2008, p. 85), compreendemos que seu uso exprime as decisóes políticas que assumimos. Se no diálogo com os/as usuários/as, os/as profissionais de saúde assumem concepções categóricas negativas sobre os símbolos e elementos negros, estes reforçam o fosso da exclusão racial e social que incide sobre a saúde destes grupos.

\section{$\mathrm{O}$ mito da incomum capacidade para resistir à dor}

Algumas falas tratam de estereótipos racistas atribuídos à mulher negra e sua comparação com a branca, no que se refere aos aspectos reprodutivos. As participantes 
relatam a existência de um imaginário racista que atribui uma suposta predisposição biológica das mulheres negras para suportar a dor.

A ideia é de que a mulher negra aguenta dor. Ela pode ser cortada, ela vai ter um menino
mais facilmente porque é parideira, tem muito isso! A branca é estreitinha, é delicada, é
sensível. Mas a negra não, essa tem quadril largo (Raquel).
[...] quando a mulher é negra eles têm a tendência de deixar mais tempo pra ver o quanto
ela aguenta de dor, geralmente é mais maltratada [...] eu chorava muito, gritava: é muita
dor, muita dor! Se for uma mulher branca, o atendimento é rápido, num instante. Já a
mulher negra... "deixa ela aí!" (Zizi).

Ao caracterizar a mulher negra como aquela que "aguenta dor" remete-se à banalidade, um assentimento ao sofrimento. Um discurso colonizador utilizado para fundamentar à desumanização do sujeito negro além de uma suposta submissão e predisposição inerente ao trabalho exaustivo.

A ciência moderna naturalizou uma superioridade branca em detrimento de uma inferioridade negra baseando-se em pressupostos biologicistas criados para justificar a escravidão do negro africano (OLIVEIRA, 2012). Para o pensamento colonial, a força e a subserviência eram características naturais desta raça, assim como a ausência da razão e lógica (MBEMBE, 2014). Séculos depois, "os cientistas, após muitas reticências, admitiram que o preto era um ser humano; in vivo e in vitro o preto tinha-se revelado análogo ao branco; mesma morfologia, mesma histologia" (FANON, 2008, p. 111). No entanto, o racismo se mantém atestando que a raça é uma construção histórica e social determinada por uma relação de dominação e exploração econômica, cultural e epistêmica.

$\mathrm{Na}$ fala de Raquel, os atributos utilizados à mulher negra como "parideira", de "quadril largo", em oposição à branca "estreitinha", simbolizam o pensamento de que as mulheres de descendência africana possuem um alto valor reprodutivo. A historiadora Jennifer Morgan (1997) descreve que, no século XVII era comum atribuir uma fragilidade à mulher branca e o momento do parto era um ponto importante para esta comparação. Enquanto a mulher africana e indígena possuía uma facilidade em dar à luz, de forma aparentemente indolor, as brancas sofriam ao parir por serem descendentes diretas de Eva. No mito bíblico, como punição pelo pecado original, a mulher passaria pela rigidez da gravidez, à dor e riscos do parto. Médicos ingleses escreviam, em meados do mesmo século, sobre a propensão das mulheres africanas para o parto fácil, e por serem mais resistentes, poderiam realizar 
trabalhos duros enquanto amamentava sua prole (MORGAN, 1997). A esta mulher, e este corpo, é negada uma condição de humanidade plena.

No contexto de escravidáo no Brasil, Sonia Giacomini (1988) relata que a gravidez, maternidade e a amamentação se traduziam em penalidades adicionais às mulheres, pois esperavam que estas fossem tão produtivas quanto os homens. As funções que desempenhavam, seja na plantação ou na casa-grande, dobravam: "a negligência e o descaso dos senhores no tratamento da reprodução escrava parecem ter punido duplamente a portadora do ventre-gerador." (GIACOMINI, 1988, p. 26). Neste aspecto não havia distinção de sexo, a força era algo natural e atribuída à raça, ao corpo negro (DAVIS, 2016).

O discurso consistia em atestar a superioridade branca e construir um ser desprovido de humanidade. A mulher de descendência africana era reduzida a uma mercadoria, destituída de elementos considerados femininos como sensibilidade e fragilidade, suas "potencialidades" estavam na capacidade de aguentar o trabalho extenuante e a reproduçáo forçada. Aos poucos foi criado o modelo de mulher negra de personalidade forte e sólida. A luta pela sobrevivência presente na vida dessas mulheres muitas vezes se traduz em assumir uma posição mais "dura" diante das próprias feridas.

Seguindo com a narrativa de Zizi, uma mulher angolana, esta referiu uma dor insuportável durante as contraçóes: "eu chorava muito, gritava, é muita dor, muita dor!". E que escutava da médica que a assistia à recomendação "guarde suas forças pra tirar seu filho!". Afirmou que em momento algum foi oferecido quaisquer métodos para alívio da dor pela equipe que a acompanhava. É certo que a dor é própria da fisiologia normal do parto, ela vai indicar as etapas do processo do nascimento desde a fase de dilatação até o período expulsivo. Segundo recomendações do Ministério da Saúde, a realização de técnicas não farmacológicas são as mais recomendadas para atenuar a dor no trabalho de parto, em contraponto a analgesia medicamentosa (BRASIL, 2017).

Um estudo de base populacional e abrangência nacional observou que mulheres pretas recebem menos anestesia local quando submetidas à episiotomia, incisão no períneo realizada com uma tesoura ou bisturi. Os resultados também mostram que mulheres negras (pretas e pardas) têm os piores indicadores de assistência no pré-natal e parto, em comparação às brancas (LEAL et al., 2017). A partir destes dados, questionamos se os profissionais de saúde baseiam suas açôes em visôes 
estereotipadas e preconceituosas do corpo negro. Persiste no imaginário social a crença de que mulheres negras são naturalmente mais resistentes à dor?

As disparidades na saúde reprodutiva que permeiam a vida de mulheres negras são efeitos de um histórico de opressóes estruturais de raça, bem como classe, gênero e cultura, produzindo as desigualdades reprodutivas. A estas disparidades que sobrecarregam as mulheres negras produzem o que a antropóloga negra estadunidense Dána-Ain Davis (2018) nomeia racismo obstétrico.

A autora do artigo Obstetric Racism: The Racial Politics of Pregnancy, Labor and, Birthing, observa o nascimento prematuro de bebês negros para estudar o racismo nos encontros médicos em hospitais dos Estados Unidos. Segundo Davis (2018), o racismo obstétrico reside na intersecção entre violência obstétrica e racismo médico, ou "racismo em saúde", como fenômeno da extensão da estratificação social e estigmatização historicamente construída sobre as mulheres negras.

Em uma das narrativas descritas, a entrevistada atribuiu a negligência nos cuidados na gestação ao racismo, e afirmou que o nível inferior de cuidado estaria ligado a estereótipos racistas. Para Davis, a ausência de condiçôes clínicas racializadas que supostamente a classificaria como uma gestante de alto risco, como diabetes e hipertensão, fez com que o médico tomasse uma postura negligente, desconsiderando a preocupação que ela tinha com a gestação. Ao dar à luz a gêmeos com apenas 26 semanas de gestação, a entrevistada ouviu comentários da equipe da UTI neonatal sobre a força dos bebês negros e sua capacidade de maior sobrevida. Um mês depois, um dos seus filhos foi a óbito por infecção hospitalar. Para a autora, o racismo médico se dá quando a ideia de raça vai influenciar as percepçôes dos profissionais de saúde no diagnóstico e tratamento dos pacientes (DAVIS, 2018). Possivelmente, os custos de se racializar a força e a sobrevida das crianças negras são de que estas estarão sujeitas a receberem menos atençáo e cuidado.

O racismo cotidiano revive cenas do passado colonialista, cuja "ferida do presente ainda é a ferida do passado e vice-versa; o passado e o presente estrelamse como resultado (KILOMBA, 2019, p. 158). Em um país que carrega os legados da colonização e escravização, muitas mulheres negras compreendem a partir de suas realidades, que o racismo e o sexismo afetam suas histórias de gestação, parto, puerpério e maternidade. Assim, quando profissionais de saúde realizam uma intervenção cirúrgica em uma mulher preta sem fazer uso de anestesia é um lembrete da nossa história racial, uma expressão do racismo em saúde. 


\section{A rotina hospitalar e o racismo religioso}

As práticas hospitalares muitas vezes excluem o sujeito, que passa ser um corpoobjeto, e diversas outras terapêuticas no processo do cuidado. As participantes pertencentes a religião candomblé, falam sobre suas experiências e percepções ao usarem elementos espirituais no contexto hospitalar.

Para ter o [filho] mais velho, eu fui com a faixa amarela. "Você tem que tirar, você tem que tirar!", me disseram. Só que eu não podia tirar. Mas graças a Deus entenderam porque minha tia é de lá, e é do candomblé também, filha de Iemanjá. Aí eu subi com a faixa, tive meu filho com a faixa. Quando eu subi de novo, o médico disse: "você tem que tirar isso, viu!". A enfermeira: "é sobrinha de Rita doutor, tem que deixar, ela é do Candomblé”, falou baixinho (Loní).

Eu nem tava com "fio", só tava só com um idé que é uma pulseira que é referente a minha Orixá. Eu nem botei "fio" até porque eu sei que aqui [Pernambuco] é mais intolerante. Então, eu já "calçada" das minhas artimanhas, botei uma coisa que ninguém vai saber o que é, quem não é de "santo" não vai saber (Magnólia).

A primeira fala descreve um desrespeito do profissional médico sobre os caminhos terapêuticos realizados pela parturiente. A medicina age segundo um determinismo científico, desconhecendo os cuidados e sistemas de cura seculares das religiôes de matrizes africanas e indígenas. Quando há um reconhecimento acerca destas práticas geralmente são colocadas como secundárias, próprias de uma crença muito específica de alguns poucos sujeitos. Para as participantes, os cuidados espirituais não se apresentam como mais uma opção terapêutica, mas como algo inerente à sua subjetividade. É a manutenção, dos saberes e práticas herdadas por seus ancestrais.

A faixa amarela usada por Loní, representa uma continuação dos cuidados realizados durante toda a gestação para um parto seguro. As participantes relataram que tiveram que realizar vários rituais referentes a orixá Oxum: banhos, ebó ("oferendas") e presentes foram dados a esta divindade africana das águas doces e da fertilidade. Em outro momento da entrevista, Magnólia ressalta: "a gente que vive o sagrado no candomblé tem outras possibilidades de cura, outros entendimentos de cura que não é medicamentoso, não é alopático". O corpo seu equilíbrio, ou desequilíbrio, não se encerram nas dinâmicas vitais da fisiologia humana. No candomblé, alguns ritos tratam de um processo subjetivo de harmonização do corpo e da mente (Orí). Neste aspecto, o ebó é um elemento terapêutico necessário na restituição do equilíbrio e da saúde dos adeptos a prática religiosa (GOMBERG, 2011). 
No segundo trecho, Magnólia usa o termo "intolerante", para qualificar aqueles que não respeitam as vivências religiosas dos cultos africanos, no Brasil. O medo de ser discriminada no ambiente hospitalar fez com que a entrevistada abdicasse de usar seus "guias" ou "fios de conta". Segundo as entrevistadas, tais objetos identificam os sujeitos dessas religiôes, os Orixás $^{l}$ que regem a pessoa, a nação e sua graduação na casa (ilé). Em outro momento, Magnólia relata que percebeu um tratamento hostil quando seu companheiro, que portava um fio do orixá Ogum, foi visitá-la na maternidade.

Quando ele foi pro hospital, ele foi com um fio de conta dele, um "fio de grau" que é mais grosso e dava pra notar mais. Porque, um "negáo", ainda me chega com aquilo aparecendo, aquele azuláo gritante! Aí era engraçado os olhares meio apavorados dizendo "não mexam com eles", foi uma coisa meio assim. Quase não falaram com a gente depois que o João chegou com aquele fio, aí de fato são "macumbeiros”! Teve gente que teve dificuldade de falar depois, não olhava no olho da gente (Magnólia).

Observamos que, gestos, olhares e mudanças repentinas no tratamento produziram efeitos na forma do "não dito", expresso no comportamento hostil dos indivíduos naquele local. É preciso ter a compreensão de que o racismo não se reduzir às falas pejorativas, que tem a intenção em ofender ou depreciar. A discriminação pode ocorrer através de um jogo de linguagem náo verbal. $O$ discurso silencioso, evidenciado pelas açôes corporais, elucidam que na experiência de Magnólia, o racismo religioso não se manifestou na fala, mas no corpo. "As relaçóes raciais constituem, nesse caso, um jogo de linguagem não verbal, não dito, discurso silencioso, mais corporal do que verbal, pelo qual os indivíduos mobilizam as forças, os corpos e os acontecimentos sociais, e se apropriam deles" (SALES JR., 2006, p. 243).

$\mathrm{O}$ racismo transcorre em várias esferas, nas categorias racializadas: "[...] marcado pela cor, pela etnia, pela língua, pela cultura, ou pela religiâo" (GROSFOGUEL, 2012, p. 93). No Brasil as hierarquias étnico/raciais estão marcadas pela cor da pele, fenótipo e por determinadas práticas religiosas. Nascimento (2017, p. 54) enfatiza uma importante questão: "a hegemonia das crenças cristãs não faz com que qualquer religião não cristã seja atacada da mesma forma”. O autor se refere à insuficiência da ideia de intolerância religiosa para se referir às discriminaçôes contra as comunidades tradicionais de matrizes africanas.

Com o crescente movimento neopentecostal no Brasil, os ataques vêm sendo cada vez mais recorrentes e públicos. O medo de ser hostilizado ou de lhe negarem 
atendimento pode ser um fator de impedimento para os praticantes dessas tradiçôes de buscarem os serviços públicos de saúde. $\mathrm{O}$ fato de pertencer a uma religião de matriz africana e indígena agrava ainda mais a situação dos negros em nosso país. $\mathrm{O}$ combate ao preconceito étnico e religioso no Brasil é, sobretudo, um enfrentamento à herança colonial do racismo.

Logo, o fenômeno caracterizado de racismo religioso conversa mais com esse processo de demonização, discriminação e criminalização dos cultos de matrizes africanas. Lembrando que, "a própria exotização e demonização é um produto do racismo.” (NASCIMENTO, 2017, p. 53). Não se trata apenas de ter elementos ritualísticos originários da África em sua constituição, mas de trazer uma série de outros modos não hegemônicos de compressão sobre a vida, a família, a economia e a comunidade. E no que se refere às mulheres negras, Carneiro (2003, p. 2) vai afirmar que, nós "fazemos parte de um contingente de mulheres originárias de uma cultura que não tem Adão. Originárias de uma cultura violada, folclorizada e marginalizada, tratada como coisa primitiva, coisa do diabo[...]”.

Não estamos tratando apenas de um repúdio aos rituais, crenças ou a relação com o sagrado, mas ao modo de vida herdado pelo negro africano, incluindo seus saberes de cura. As religióes de matrizes africanas e indígenas, e seus cuidados terapêuticos, são a resistência em um mundo que não enxerga o negro. As comunidades de Axé, além de serem espaços de cultos, orientam para uma formação humana baseada na reflexão sobre a realidade do povo negro no Brasil. São espaços de resgate de símbolos, línguas e culturas que não mais existem na África, onde se vive este continente ao seu modo em nosso solo, de forma singular e talvez idílica. Conclui-se que, a experiência da comunidade foi indispensável à própria sobrevivência do negro africano em diáspora.

\section{Considerações finais}

Buscamos neste artigo estimular a discussão sobre o racismo a partir das experiências e percepções de mulheres negras no contexto de atenção na gestação e no parto. Estas falam com base em suas posiçôes políticas, antirracistas e vivências religiosas sobre um dos temas ainda negligenciados na saúde, o debate racial. Questiona-se se os motivos de evitarmos falar sobre a questão racial é movido por uma aversão ao nosso legado racista, ou se pela ausência de uma compreensão de sua existência? 
É certo que, enquanto nação, fomos constituídos com a ideia de vivermos em plena harmonia racial, sem qualquer distinção ou privilégios. Sob a "sombra" desse mito, nega-se a existência do racismo como produtor de invisibilidade, tratamento desigual e menor prestígio social a população negra. Enquanto alimentamos a ficção de uma democracia racial, onde as mesmas oportunidades são dadas a todas as pessoas, garantidas mediante seus esforços e seu caráter individual, perpetuamos as disparidades e conflitos raciais.

Para aquelas pertencentes às religióes de matriz africana, a incorporação de práticas de cuidado da gestação e parto, valores orientados pela tradição, são comuns e buscam uma harmonia entre o corpo e o sagrado. Elas descrevem um equilíbrio necessário entre a gestante e as forças da divindade africana que protege o útero das mulheres. Sugerimos um olhar de respeito e reconhecimento desses lugares como importantes espaços de construção e trocas de saberes voltado à saúde.

Defendemos que ao analisar saúde da população brasileira, em qualquer fase da vida ou gênero, não se deve diminuir a importância da raça como categoria estruturante do acesso à saúde integral. Quando pesquisamos sobre a saúde da mulher no período da gestação ao pós-parto, por exemplo, nos deparamos com várias iniquidades raciais que geralmente são invisibilizadas no debate mais amplo acerca dos direitos reprodutivos. Nas relaçóes interpessoais, a reprodução de discursos permeados por estereótipos racistas desumaniza a mulher negra, criando um afastamento desta aos cuidados na gestação, parto e puerpério.

Sugerimos mais estudos sobre o tema do racismo institucional na saúde gestacional, perinatal, saúde sexual e reprodutiva, e demais campos da Saúde Coletiva. Analisar o que foi feito em termos de políticas públicas nas últimas décadas, as perspectivas futuras e pensar propostas para a mudança de um quadro de iniquidade, principalmente em tempos de cerceamento de direitos, são outros pontos que podem ser abordados em estudos futuros. Os desafios estão além do campo acadêmico e se mostram cada vez mais necessários na proposiçâo de açôes efetivas que busquem por elidir as iniquidades raciais em saúde. ${ }^{2}$

\section{Referências}

BARDIN, L. Análise de Conteúdo. São Paulo: Edições 70, 2011.

BRASIL. Ministério da Saúde. Secretaria de Ciência, Tecnologia e Insumos Estratégicos. Diretrizes nacionais de assistência ao parto normal. Brasília: Ministério da Saúde, 2017. 
CARNEIRO, S. Enegrecer o feminismo: a situação da mulher negra na América Latina a partir de uma perspectiva de gênero. Racismos contemporâneos. Rio de Janeiro: Takano, 2003. p.49-58.

DAVIS, A. Mulheres, raça e classe. São Paulo: Boitempo, 2016.

DAVIS, D-A. Obstetric Racism: The Racial Politics of Pregnancy, Labor, and Birthing. Journal Medical Anthropology, 2018.

FANON, F. Pele negra, máscaras brancas. Salvador: EdUFBA, 2008.

FERNANDES, F. A integração do negro na sociedade de classes. São Paulo: Globo, 2008.

FERNANDES, N.V.E. A raiz do pensamento colonial na intolerância religiosa contra religióes de matriz africana. Calundu, v. 1, n. 1, 2017.

GIACOMINI, S.M. Mulher e Escrava: uma introdução histórica ao estudo da mulher negra no Brasil. Petrópolis: Vozes, 1988.

GOMBERG, E. Hospital de Orixás: encontros terapêuticos em terreiro de candomblé. Salvador: EdUFBA, 2011.

GOMES, N.L. Sem perder a raiz: corpo e cabelo como símbolos da identidade negra. Belo Horizonte: Autêntica, 2006.

GROSFOGUEL, R. El concepto de "racism” en Michel Foucault y Frantz Fanon: ¿teorizar desde la zona del ser o desde la zona del no-ser? Tabula Rasa, n.16, p. 79-102, 2012.

KAMAU featuring SAPIÊNCIA, R; FREITAS, T. Tambor. São Paulo: Plano audio: 2008.

KILOMBA, G. Memórias da plantação: episódios de racismo cotidiano. Rio de Janeiro: Cobogó, 2019.

LEAL, M. C. et al. A cor da dor: iniquidades raciais na atenção pré-natal e ao parto no Brasil. Cadernos de Saúde Pública, v. 33, supl. 1, 2017.

MBEMBE, A. Crítica da razão negra. São Paulo: Antígona, 2014.

MORGAN, J. L. "Some Could Suckle over Their Shoulder": Male Travelers, Female Bodies, and the Gendering of Racial Ideology, 1500-1770. The William and Mary Quarterly, v. 54, n. 1, p. 167-192, 1997.

NASCIMENTO, A. O Genocídio do negro brasileiro: processo de um racismo mascarado. São Paulo: Perspectivas, 2016a.

NASCIMENTO, W. F. O fenômeno do racismo religioso: desafios para os povos tradicionais de matrizes africanas. Eixo, v.6, n.2, p. 51-56, 2017.

. Sobre os candomblés como modo de vida: imagens filosóficas entre Áfricas e Brasis. Ensaios Filosóficos, v. 13, p. 153-170, 2016 b. 
OLIVEIRA, E. D de. Filosofia da Ancestralidade como Filosofia Africana: educação e cultura afro-brasileira. Revista Sul-Americana de Filosofia e Educação, n.18, p. 28-47, 2012.

SALES JR., R. Democracia racial: o não-dito racista. Tempo Social, v.18, n. 2, p. 229-258, 2006.

SCHWARCZ, L. M. Nem preto nem branco, muito pelo contrário: cor e raça na sociabilidade brasileira. São Paulo: Claro Enigma, 2012.

SILVA JR., H. A intolerância religiosa e os meandros da lei. In: NASCIMENTO, E.L. (Org.). Guerreiras de natureza: mulher negra, religiosidade e ambiente. São Paulo: Selo Negro, 2008. p. 169-188.

SOUZA, N. S. Tornar-se negro: as vicissitudes da identidade do negro brasileiro em ascensão social. Rio de Janeiro: Ediçôes Graal, 1983.

THEODORO, H. Mulher negra, cultura e identidade. In: NASCIMENTO, E.L. (Org.). Guerreiras de natureza: mulher negra, religiosidade e ambiente. São Paulo: Selo Negro, 2008. p. $85-96$.

WERNECK, J. Racismo institucional e saúde da população negra. Saúde e Sociedade, v.25, n.3, p. 535-549, 2016.

\section{Notas}

${ }^{1}$ As "divindades" recebem os nomes de Orixás, nos candomblés de origem iorubá, de Inquices, nos candomblés de origem banta e Voduns, nos candomblés de origem ewé-fon (dahomeana). Estas figuras representam - e são responsáveis - ora por uma força da natureza, ora por um fenômeno da experiência humana (NASCIMENTO, 2016b, p. 157).

${ }^{2}$ K. D. Lima realizou a pesquisa, analisou os resultados e redigiu o artigo. L. Lewis e T. M. Lyra orientaram a pesquisa e a análise dos resultados, participaram da redação e da aprovação da versão final do artigo. 


\title{
Abstract
}

\author{
"The dark of colors, in the afro-descendant \\ skin, heir of pain": dimensions of racism in the \\ context of childbirth care
}

Starting from a broader research on the experiences of black women in assisting the gestational period and childbirth, this article addresses some aspects of racism in the routine of care for black women during this cycle. This is an empirical research with a qualitative approach with women and mothers who declare themselves black and anti-racist. In the narratives, the points presented involved, for the most part, stereotypes associated with the black body constructed under a racist social imaginary. In interpersonal relationships, speeches permeated by racist stereotypes dehumanize black women, creating barriers in their reproductive health.

> Keywords: black women; racism; racial discrimination in health; delivery assistance; reproductive rights. 